\title{
Blood concentrations of lead and mercury in British Columbians (2009-2010)
}

\author{
Gagandeep Dhillon ${ }^{1}$, Helen Heacock², Dr. Reza Afshari ${ }^{3}$
}

1 Lead Author, B. Tech Student, School of Health Sciences, British Columbia Institute of Technology, 3700 Willingdon Ave, Burnaby . 2 Supervisor, School of Health Sciences, British Columbia Institute of Technology, 3700 Willingdon Ave, Burnaby.

3 Contributor, Senior Scientist, Toxicology, British Columbia Centre for Disease Control, Vancouver.

\section{Abstract}

Background and Purpose: Adverse effects of lead and mercury on human health due to environmental and occupational exposures require a public health attention. These metals can cause severe harm to vulnerable populations such as children and pregnant women. The probability of chronic and harmful exposure is higher in occupational settings. Monitoring the levels of these two metals in blood is an important tool to identify and quantify exposure to these metals in the environment. Monitoring data provides vital information required for management of health risk posed by these metals. The purpose of this study was to perform a comparative analysis of blood lead levels and blood mercury levels within the province of British Columbia on the health services data obtained from BC Centre of Disease Control. The primary objective was to compare the levels of lead and mercury in blood among different health authorities of British Columbia. The secondary objective was to compare the levels of lead and mercury among different age groups and gender.

Methods: The blood lead and mercury concentrations used for the analysis were provided by Environmental Health Services at the British Columbia Centre for Disease Control (BCCDC). The data comprised of blood analyses that were ordered by physicians during the period of 2009-2010 for reasons not disclosed. Access to this data was provided by Dr. Reza Afshari with the permission of Dr. Tom Kosastsky for the completion of this project only. Statistical analysis of data was performed using Microsoft Excel 2013 and SAS University Edition Analytic Software. Various descriptive and inferential statistical tests were performed on the data to determine the differences of blood mercury and lead levels among different genders, Health Authorities and age groups.

Results: The levels of blood mercury and lead concentrations were not significantly different in males and females in province (p-value 0.5543 for mercury; $p$-value 0.5336 lead). However, it was found that blood levels of lead were higher in Interior Health and "Unknown" category $(p<0.02)$, while blood mercury levels were significantly higher in coastal health authorities (highest in Vancouver Coastal Health Authority, followed by Fraser Health Authority and Vancouver Island Health Authority) $(p<0.001)$. For both toxic metals, levels were highest in age group of 50 and above. ( $p<0.0001$ for mercury, $p<0.02$ for lead).

Conclusion: The statistical analysis of lead and mercury data was useful in characterizing the exposure among Health Authorities, age and sex of the people tested in province of British Columbia. Analysis of mercury data has generated clear patterns inferring association between coastal Health Authorities and elevated mercury levels. Vancouver Coastal Health had highest median mercury levels $4.02 \mu \mathrm{g} / \mathrm{L}$ higher than other health authorities $(p<0.0001)$. Analysis of lead data established a pattern among physicians suggesting that they are more likely to order a test if the patient is under 18 years of age. Median levels were found to be highest in Interior Health Authority and "Unknown" (1.66 $\mu \mathrm{g} / \mathrm{dL}$ ). Higher levels in Interior Health could have been due to occupational exposure to lead in Trail BC area.

Keywords: Lead, mercury, pregnancy, children, British Columbia, blood lead levels, blood mercury levels, Vancouver Coastal Health, Fraser Health, Interior Health, Northern Health, Vancouver Island Health Authority, occupational exposure. 


\section{Introduction}

We are exposed to numerous chemicals every day - in the air, food and water, at home and at play. Exposure to most of these chemicals is not harmful. But in some cases exposure can affect our health if risks are not properly managed. Heavy metals such as lead and mercury are toxic to humans and have been widely studied over the years for their adverse health effects. The purpose of this project was to do a comparative study of lead and mercury blood levels among the population of British Columbia based on the data available for year 2009-2010. The primary objective of the study was to compare the blood concentrations of lead and mercury among different health authorities in British Columbia. The secondary objective of the study was to compare the blood concentrations of lead and mercury among different gender and age groups of population of British Columbia.

\section{Evidence Review}

\section{Lead}

Lead is a naturally occurring environmental contaminant with a low melting point and bluish gray appearance, found in the crust of the earth (Abadin, et al., 2007). Human activities such as the use of leaded gasoline, the burning of fossil fuels, and the manufacture of lead alloys have led to a significant increase in levels of lead in the environment (Abadin, et al., 2007). Lead poses a significant risk to the health of Canadians due to its broad exposure among general public while having a considerable toxic potential (Health Canada, 2013). Lead can be harmful to people of all ages, although infants and children are the most susceptible (Abadin, et al., 2007). Their susceptibility is higher because their growing bodies absorb lead more readily and are less efficient at eliminating it (Health Canada, 2013). The majority of lead exposure in the case of infants is caused by maternal transfer during pregnancy (Taylor, Golding, Hibbeln, \& Emond, 2013). Higher levels of lead in blood is a clear indicator of a health risk to the individual. The toxic potential of lead cannot be underestimated as new scientific information has shown that blood levels of lead that were previously considered safe, can now cause adverse health effects (Rooney, et al., 2012).
The current blood lead intervention level for the Canadian population is $10 \mu \mathrm{g} / \mathrm{dL}$. The average lead levels in blood in Canadians as reported by Statistics Canada in a 2009 -2011 report was $1.2 \mu \mathrm{g} / \mathrm{dL}$ for the age group of $6-79$ years old (Statistics Canada, 2013).

\section{Mercury}

Mercury is another naturally occurring environmental contaminant that occurs in elemental form, inorganic form and organic form. Methylated mercury is the most common organic mercury compound found in nature. Elemental mercury is a brilliant shiny metal and exists as a liquid at room temperature. This metal can be commonly found in old thermometers, fluorescent bulbs and light switches (United States Environmental Protection Agency, 2015). For the general population in Canada mercury exposure primarily occurs due to its use in workplaces (e.g. dental amalgam) and due to consumption of fish (organic mercury) (Brodkin, et al., 2007). Mercury can cause adverse health effects in people of all ages and gender, however pregnant women, young children and people with impaired kidney function are at an elevated risk (Health Canada, 2009). Elevated levels of mercury in blood can cause implications such as a decrease in $\mathrm{IQ}$, blindness and seizures in children. In adults, higher levels can lead to loss of muscle coordination and sensation, tremors, memory loss and even death (Health Canada, 2009).

The current blood intervention level for mercury in Canada is established by Health Canada guideline. The level is set at $20 \mu \mathrm{g} / \mathrm{L}$ for the general adult population. This intervention level has been set at 8 $\mu \mathrm{g} / \mathrm{L}$ for children, pregnant women and women of child bearing age. Average blood mercury levels for Canadians aged 3-79 years is $0.79 \mu \mathrm{g} / \mathrm{L}$ according to 2012-2013 data available from Health Canada (Statistics Canada, 2015). It should be noted that blood mercury levels are primarily an indicator of organic mercury (methylated mercury (Health Canada, 2009).

According to Health Canada, lead is one of the most extensively regulated toxic metals in Canada. The lead concentrations in the environment have drastically diminished due to the implementation of lead reduction strategies such as the introduction of unleaded gasoline, and the regulation of lead paint and solder (Health Canada, 2013). Similarly, regulatory and non-regulatory initiatives from both 
provincial and federal governments have resulted in a $90 \%$ reduction in sources of anthropogenic mercury in Canada since the 1970's (Environment Canada, 2010). Reduced environment concentrations have resulted in lower blood level concentrations of lead and mercury (lower than respective intervention levels) in the Canadian population (Statistics Canada, 2015). But these two heavy metals still exist in the environment and a chronic and high level exposure to these metals is very dangerous.

\section{Health effects of low levels of lead and mercury}

The Canadian blood intervention level for lead has been set at $10 \mu \mathrm{g} / \mathrm{dL}$ (Health Canada, 2013; Statistics Canada, 2013; Health Canada, 2013; Stares \& Kostasky, 2014; Health Canada, 2013). The National Toxicology Program of the US Department of Health and Human Services, has published a document based on epidemiological evidence from almost 28,900 publications in peer reviewed literature to reach a conclusion that health effects are associated with a level lower than the Canadian blood intervention level (Rooney, et al., 2012). This document published in June 2012, has divided the epidemiological evidence into categories of i) Sufficient evidence ii) Limited evidence iii) Inadequate evidence based on association of lead levels to health outcome and ability to rule out bias and confounding. According to this document, blood lead levels of $>10 \mu \mathrm{g} / \mathrm{dL}$ and $>5 \mu \mathrm{g} / \mathrm{dL}$ in adults and children respectively, are associated with health outcomes such as lower IQ, maternal blood transfer, hypertension, delayed puberty and attention related disorders (Rooney, et al., 2012). On the contrary, there is insufficient evidence to suggest that lower levels of mercury in blood $(<20 \mu \mathrm{g} / \mathrm{L})$ can produce adverse health effects (Karagas, et al., 2012).

\section{Health effects on infants and children}

A population based cohort study conducted by Evens and colleagues in Chicago Public Schools (US) concluded that early childhood exposure to lead is associated with poor grades in math and reading tests (Evens, et al., 2015). The US Centre for Disease Control lowered the acceptable blood lead levels from $30 \mu \mathrm{g} / \mathrm{dL}$ to $25 \mu \mathrm{g} / \mathrm{dL}$ in 1985 to $10 \mu \mathrm{g} / \mathrm{dL}$ in 1991 (Rooney, et al., 2012). This decrease in the acceptable blood lead levels is based on the information available on adverse health effects of lead on children health (Rooney, et al., 2012). In a clinical review, Abelsohn and Sanborn have argued that blood lead levels should be reduced to $2 \mu \mathrm{g} / \mathrm{dL}$ based on the current evidence (from $10 \mu \mathrm{g} / \mathrm{dL}$ ) (Abelsohn \& Sanborn, 2010).

Similarly, significant evidence available from research and epidemiological studies suggest that neonates and fetuses are highly susceptible to mercury toxicity. Some of the older cohort studies from New Zealand and Faroe Islands have provided a strong evidence of reduced central nervous system development and lower IQ in children of mothers having prenatal exposure to methyl mercury (Mergier, et al., 2007). Consequently, Health Canada has recommended a revised guidance value of blood mercury level as 8 $\mu \mathrm{g} / \mathrm{L}$ for children, pregnant women and women of child bearing age.

\section{Health effects on pregnant women}

Pregnancy is a critical time for exposure to lead and mercury for the mother as well as her fetus. Taylor and colleagues have suggested that it is very important to identify the factors that can contribute to maternal blood lead levels because a mother with a high level of lead in her blood can easily transfer this lead to her fetus through the placenta (Taylor, Golding, Hibbeln, \& Emond, 2013). A cohort study conducted in the UK, looked at risk factors that contribute to increased levels of blood lead levels in expectant mothers. Surprisingly, lead concentrations were higher in educated women. The report hypothesized that exposure at educational institutes and older homes with lead paint as key reasons. These factors can be easily related to living conditions of developed countries such as Canada and the US (Taylor, Golding, Hibbeln, \& Emond, 2013). Like lead, mercury is also able to cross the placenta and enter the fetal blood circulation system (Solan \& Lindow, 2014). A major incident where high level exposure to mercury in pregnant women has led to significant neurological defects in their offspring was the Minamata Bay incident in Japan. Chisso Company dumped 27 tonnes of mercury into the Minimata Bay. The Bay provided fish to thousands of residents in the area. A study group in Kumamoto University School of Medicine in Japan found that the disease and symptoms they were observing among residents was attributed to methylmercury poisoning caused by consumption of mercury contaminated fish. Infants 
with congenital exposure to mercury displays cerebral-palsy-like symptoms such as mental retardation, primitive reflexes, ataxia, dysarthria, and deformity of posture (Solan \& Lindow, 2014). Moreover, studies indicate that the concentration of mercury in cord blood in a pregnant woman is $70 \%$ higher than maternal blood concentration, making the fetus even more susceptible to toxicity (Solan \& Lindow, 2014).Monitoring of blood mercury and lead levels in pregnant woman are very critical in safeguarding the fetus health.

\section{Occupational exposure}

Many worry about exposure to these harmful metals in their homes and environment (soil, water and air), while for some people, their workplace might offer the greatest potential for exposure. Though used less often now, lead is still common in many industries including mining, construction and manufacturing in British Columbia. The National Institute of Occupational Safety and Health (NIOSH) has provided a guidance document that provides information about the potential routes of exposure to lead. The three major routes of lead exposure are ingestion, inhalation and dermal (physical contact with lead) absorption ((NIOSH), 2013). Taylor and colleagues expressed their concerns about high levels of lead dust settling on the playground surfaces around a lead smelter in city Port Pirie in South Australia. They advocated the use of remediation methods to lower the levels of lead dust and thus subsequent exposure (Taylor, Camenzuli, Kristensen, Forbes, \& Zahran, 2013). Worksafe BC has composed an educational document for the people working in close vicinity to lead. It lists various steps that should be taken to reduce lead exposure at work. One such measure is continuous monitoring of lead in air and making sure that lead concentrations in air does not exceed $0.05 \mathrm{mg} / \mathrm{m} 3$ when averaged over 8 hours period (Worksafe BC, 2006). In an interesting study, Rochaa and colleagues found significant increase in BLL's of Brazilian police officers, after three days of indoor shooting training, attributed to use of lead ammunition in training (Rochaa, Sarkisb, Carvalho, Santos, \& Canesso, 2014). Health Canada's Risk Management Strategy for lead has mentioned that lead is integral part of military munitions in Canada (Health Canada, 2013). Lead therefore, can be a concern for law enforcement personnel.
On a similar note, Health Canada has listed various workplaces where the occupational exposure to mercury is most likely to occur. Some examples are electric equipment manufacturers, chemical processing plants, metal processing plants, medical facilities and waste management facilities (Health Canada, 2009). Risk management strategy for mercury mentions various steps taken by local, provincial and federal governments to reduce the occupational exposure to mercury. In order to estimate the risk among the general population, mercury threshold levels in blood, hair and urine have been established (Environment Canada, 2010). Routine monitoring of workers for levels of lead and mercury is advocated to prevent unsafe exposure and toxicity.

\section{Public health significance and rationale for study}

The adverse health effects of lead and mercury are well documented. The occupational and environmental exposure to these metals can cause medical complications. Although, average blood levels in the Canadian population are really low; lead and mercury exposure are areas that require continued biomonitoring and surveillance primarily because of their toxic potential. Health effects of high blood levels of these metals on vulnerable population such as children and pregnant women stress the importance of a robust surveillance system that can provide enough statistical data to Health Authorities for the assessment of their risk. It is difficult to predict the levels of chemicals in people using estimates or measurements of chemicals in air, soil, water, food or commercial products. These predictions require public health professionals to make assumptions about personal habits and lifestyles, and make assumptions about how the chemicals are absorbed, distributed, used and eliminated from the body (Abadin, et al., 2007).Biomonitoring and analysis of data obtained from biomonitoring provides a more direct estimate of chemical exposure. This evidence review supports the fact that knowledge of blood levels of mercury and lead is a useful method for assessing the burden of their exposure on the population of British Columbia. The purpose of this comparative study of their levels is to assist the health professionals of the province to make calculated decisions about dedicating the available resources towards the mitigation of the particular exposure. For 
example, finding higher mercury levels in the coastal Health Authorities such as Vancouver Island Health and Vancouver Coastal Health will help in providing educational programs for the population about the exposure to mercury. Similarly, characterization of lead levels within the province can help in identifying the areas with higher lead levels and the areas with lower lead levels and consequently, resources can be allocated to those areas where the levels are higher.

\section{Methods}

The methods used in this study were adapted from a similar study performed by Stares and Kosatsky (2014) which characterized exposure and morbidity related to lead in the province of British Columbia (Stares \& Kostasky, 2014). The data used was blood concentration of lead and mercury for a sample of population and not the whole population of British Columbia. The blood lead and mercury concentrations used for the analysis were provided by Environmental Health Services at the British Columbia Centre for Disease Control (BCCDC). The lead data was originally obtained by BCCDC from four sources; Vancouver Costal Health (Vancouver General Hospital Laboratory), the Provincial Health Services Authority (BC Children's and Women's Hospital Laboratory), BC Biomedical Laboratories, and Life Labs Medical Laboratory. These laboratories measured blood lead concentration using Inductively Coupled Plasma or Atomic Spectrophotometry (Stares \& Kostasky, 2014). The mercury data used in the analysis was obtained by BCCDC from two sources: BC Children's and Women's Hospital Laboratory and Life Labs Medical Laboratory. Mercury concentrations were also measured using Inductively Coupled Plasma method. These blood analyses were ordered by physicians for reasons not disclosed. Access to this data was provided by Dr. Reza Afshari with the permission of Dr. Tom Kosastsky for the completion of this project only (Afshari, 2015). The population estimates of each Health Authority (period 2009-10) provided the rate of testing in that Health Authority. This data was used to determine burden of these two toxic metals on the healthcare system within the Health Authority and the province of British Columbia.

Microsoft Excel 2013 was used to sort and organize the blood lead and mercury data into an appropriate format (Microsoft Excel 2013, 2013), so that this data can be inputted into the SAS University analytical software. SAS University edition software was then used to perform descriptive and inferential statistics on the data (SAS University Edition, 2015).

\section{Results}

\section{Lead}

Statistical analysis of blood lead concentration obtained from 1074 individuals in the province of British Columbia generated the following results. The median blood lead concentration for all the test results was $1.24 \mu \mathrm{g} / \mathrm{dL}$ and the 95th percentile was $9.11 \mu \mathrm{g} / \mathrm{dL}$. Further analysis of lead data revealed that the highest number of blood tests (564) occurred in Fraser Health. This was followed by Vancouver Coastal Health with 235 blood samples tested for presence of lead. Vancouver Island Health had lowest number with 12 blood tests. The median blood lead concentration values were found to be highest in Interior Health and Unknown, both tied at the value of $1.66 \mu \mathrm{g} / \mathrm{dL}$. Only 50 samples out 1074 were found to be above the current intervention level for lead in Canada. 10 out of these 50 samples (20\%) were children less than 5 year old from Fraser Health Authority.

\section{Mercury}

The blood samples from total of 6739 individuals who had their blood tested for mercury were statistically analyzed. The median blood mercury concentration for all the test results was $1.8 \mu \mathrm{g} / \mathrm{L}$ and the 95th percentile was $12.7 \mu \mathrm{g} / \mathrm{L}$. Statistical analysis of mercury data revealed that the Health Authority with highest number of blood samples was "Unknown". This was followed by Vancouver Coastal Health with 1332 blood samples. Northern Health had lowest number of blood tests done for mercury with number amounting to 107 in total. The median blood mercury concentration values were found to be highest in Vancouver Coastal Health for both males and females. The median blood mercury concentration for Vancouver Coastal Health was 4.02 which is considerably higher than overall median. 249 samples were found to be above the current intervention levels for blood mercury in Canada. 126 out of these 249 (50.60\%) blood samples were taken in Vancouver Coastal Health area. 59 of these 126 samples were for women aged between 19-49 years (child bearing age). 


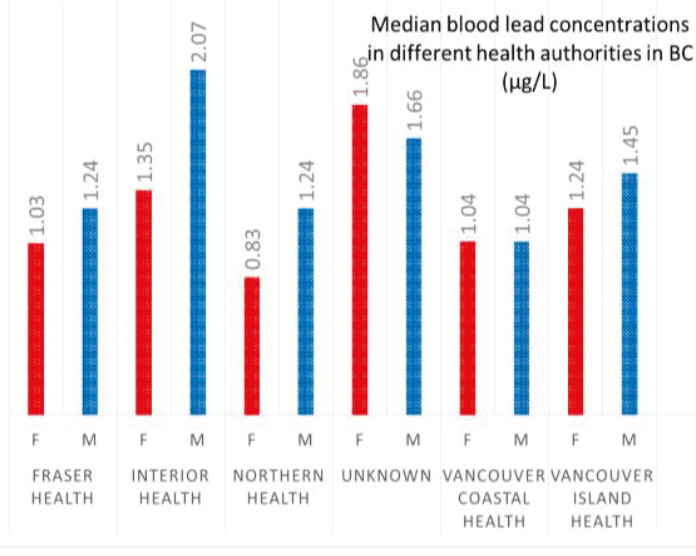

Figure 1: Median blood lead levels among different Health Authorities in BC (2009-2010)

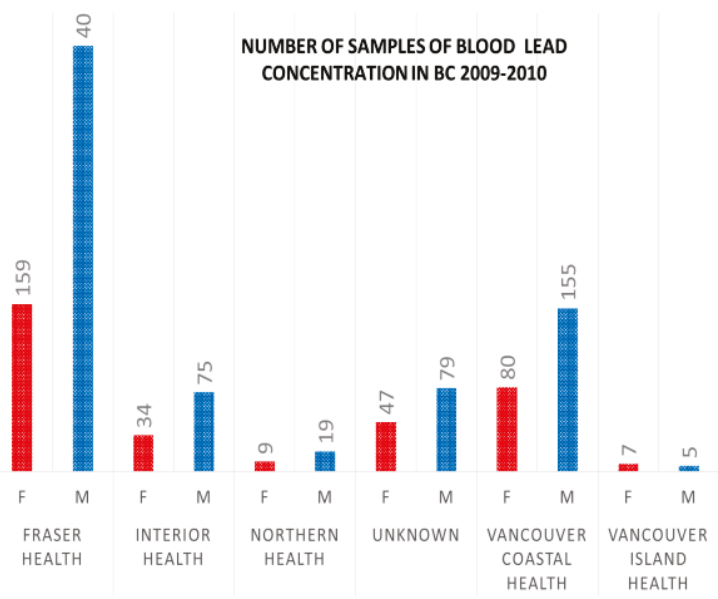

Figure 2: Number of blood lead samples in BC 2009-2010

NUMBER OF SAMPLES OF BLOOD MERCURY CONCENTRATION BC 2009-2010

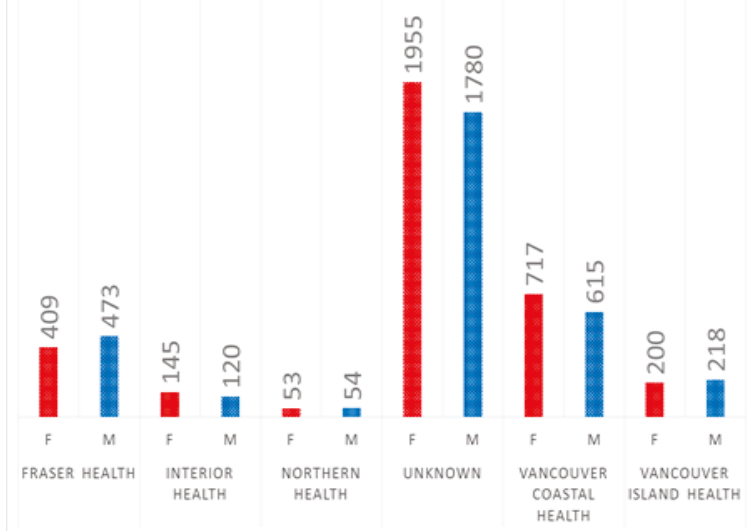

Figure 3: Number of blood mercury samples BC
Blood levels among males and females

Statistical analysis of both mercury and lead data clearly depicted that the data was not normally distributed. Inferential T-tests were performed to compare the difference between the mean blood lead levels of males and females in the province of British Columbia. Results from statistical analysis showed that there was no such difference $(p=0.5536$ $>0.05$ ). No difference was seen in case of comparison of blood mercury levels among males and females either $(p=0.5543>0.05)$.

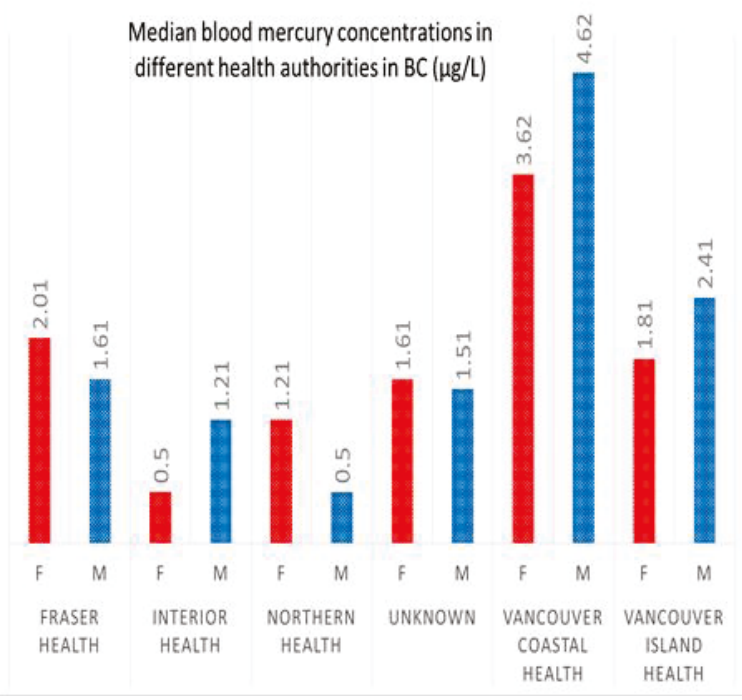

Figure 4: Median blood mercury levels among different Health Authorities in BC (2009-2010

\begin{tabular}{|c|c|c|c|c|c|c|}
\hline \multicolumn{7}{|c|}{$\begin{array}{l}\text { Least Squares Means for effect HEALTH_AUTHORITY } \\
\qquad \operatorname{Pr}>|t| \text { for HO: LSMean(j)=LSMean(j) }\end{array}$} \\
\hline \multicolumn{7}{|c|}{ Dependent Variable: BLL_ugdL } \\
\hline ijj & Fraser Health & Interior Health & Northern Health & Unknown & $\mathrm{VCH}$ & VIHA \\
\hline Fraser Health & & 0.0004 & 0.9267 & $<0001$ & 0.0818 & 0,9992 \\
\hline Interior Health & 0.0004 & & 0.0349 & 0.9953 & $<, 0001$ & 0.4644 \\
\hline Northern Health & 0.9267 & 0.0349 & & 0.0108 & 1,0000 & 0.9999 \\
\hline Unknown & $<.0001$ & 0.9953 & 0.0108 & & $<, 0001$ & 0,3197 \\
\hline VCH & 0.0818 & $<, 0001$ & 1,0000 & $<, 0001$ & & 0,9994 \\
\hline VIHA & 0.9992 & 0.4644 & 0.9999 & 0.3197 & 0.9994 & \\
\hline
\end{tabular}

Figure 5: Tukey-Kramer comparisons table for blood lead levels in different Health Authorities 


\section{Blood lead levels among different Health} Authorities and age groups of population

The statistical analysis suggested that the different Health Authorities had different mean blood lead levels $(p<0.0001)$. Post hoc testing was done to determine which Health Authority differed from one another in terms of mean blood levels. Tukey-Kramer Least mean square tables generated by SAS software that clearly show which Health Authority is significantly different from another. This difference is confirmed by $p$-value $<0.05$. The cells highlighted yellow in the table (figure 5 ) represent the significant values. For example, levels of lead in blood for Fraser Health is significantly different from Interior Health and Unknown, but not different from other Health Authorities. (Note: $\mathrm{VCH}=$ Vancouver Coastal Health, $\mathrm{VIHA}=$ Vancouver Island Health Authority)

A graphical representation of the Tukey Kramer test below clearly shows that the levels of lead in blood were higher in Interior Health and Unknown category.

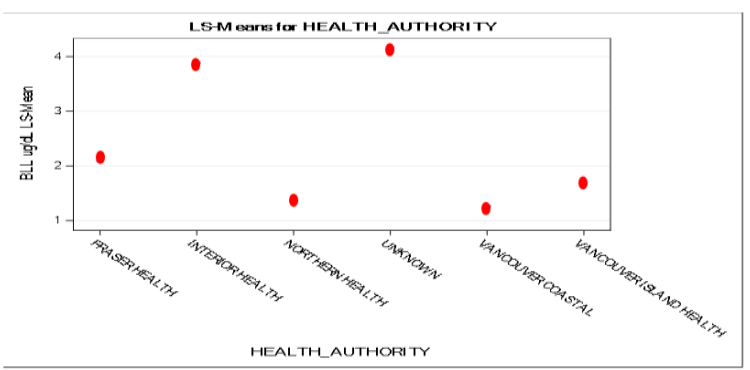

Figure 6: Tukey-Kramer comparisons for blood lead levels in different Health Authorities The Kruskal- Wallis test results for comparison of lead data among different age groups depicted a $p$-value $<0.001$. Therefore, mean blood lead levels were significantly different in different age groups.

Post hoc testing revealed that the levels of lead in blood were higher in people belonging to age groups of $19-49$ and 50 and over. These levels were lowest for people of age group 6-18 years. (Figure 7)

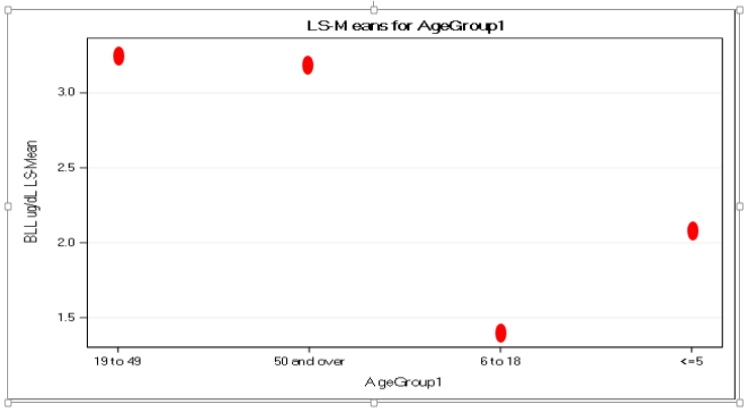

\section{Blood mercury levels among different Health Authorities and age groups of population}

Mean blood mercury concentrations levels were found to be different in different Health Authorities ( $p$-value of $<0.0001$ ).

The graphical representation of post hoc test shows that blood mercury levels were highest in samples obtained from Vancouver Coastal Health followed by Vancouver Island Health and Fraser Health. (Figure 8)

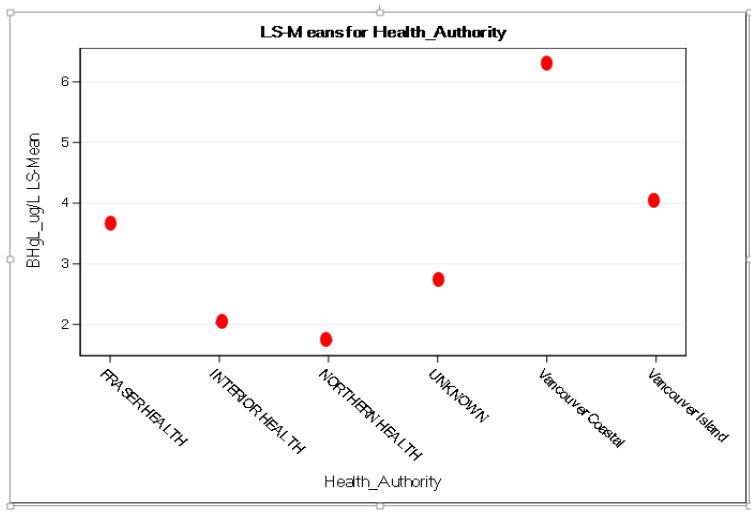

Figure 8: Tukey-Kramer comparisons (graph) for blood mercury levels in different Health

Similar post hoc tests were performed for comparing levels of blood mercury in different age groups of people tested. Results depicted a trend similar to lead data with older age groups, (19-49 and 50 \& over) had significantly higher levels of blood mercury than the other two age groups. (Figure 9)

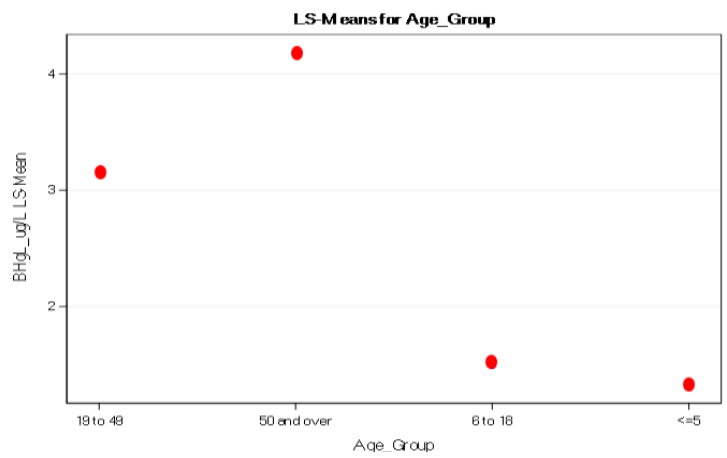

Figure 8: Tukey-Kramer comparisons (graph) for blood mercury levels in different age groups

Figure 7: Tukey-Kramer comparisons (graph) for blood lead levels in different age groups 


\section{Discussion}

\section{Demographics}

The median blood mercury concentration for 6739 individuals from British Columbia who had their blood tested was $1.8 \mu \mathrm{g} / \mathrm{L}$ and the 95 th percentile was 12.7 $\mu \mathrm{g} / \mathrm{L}$. Comparatively, the Canadian Health Measure Survey (CHMS) numbers for cycle 2 from 2009-2011 were lower at median $0.76 \mu \mathrm{g} / \mathrm{L}$ and 95 th percentile was $5.6 \mathrm{\mu g} / \mathrm{L}$ (Canadian Health Measures Survey: Cycle 2 Data Tables - 2009 to 2011, 2011). However, blood mercury levels were expected to be higher since these blood tests were ordered by physicians based on suspicion of elevated exposure among people tested. In terms of prevalence of blood mercury testing ordered by physicians in BC, approximately 15 individuals per 10, 000 had their blood tested for mercury during 2009-2010 (Population by year, by province and territory, 2015). The highest prevalence of testing among health authorities were found in Vancouver Coastal Health, closely followed by Vancouver Island Health and Fraser Health in second and third respectively. Comparatively, during the period of 2009-2010, physicians in Ontario ordered 13,282 individuals to be tested for methylmercury (Lambrinos, 2014) (Population by year, by province and territory, 2015). Prevalence of mercury testing in Ontario was lower (approx. 10 individuals per 10,000 population) than British Columbia. This suggest that exposure to elevated levels of mercury is more common in British Columbia than Ontario. Another explanation could be that suspicion of exposure to mercury is more common in British Columbia, therefore physicians order more tests.

The median blood concentration for 1074 individuals in BC who had their blood tested for lead was 1.24 $\mu \mathrm{g} / \mathrm{dL}$ and the 95 th percentile was $9.11 \mu \mathrm{g} / \mathrm{dL}$. In comparison, the median levels for blood lead levels in CHMS survey was $1.1 \mu \mathrm{g} / \mathrm{dL}$ and 95th percentile was $3.2 \mu \mathrm{g} / \mathrm{dL}$ (Canadian Health Measures Survey: Cycle 2 Data Tables - 2009 to 2011, 2011). On a similar note, elevated levels in BC can be attributed to the fact that physicians ordered blood test for these individuals with a suspicion of elevated exposure to lead. The prevalence of lead testing in British Columbia was lower than the mercury testing, with approximately 2 people tested per 10,000 . Fraser Health had most cases of lead testing with a prevalence of approx. 3.5 per 10,000 (Population by year, by province and territory, 2015). It can be hypothesized that Fraser Health had highest number of tests being ordered because $66.13 \%$ of their patients were 18 year or younger. Due to risk associated with elevated levels of lead in children, higher prevalence of tests was justified.

\section{Levels of lead and mercury among different age groups and gender}

\section{Mercury}

Children are highly susceptible to toxicity of lead and mercury. Even the levels lower than established threshold limits have been associated with significant health effects. Analysis of blood mercury levels of children $<=5$ and 6 to 18 years of indicated median levels of $0.50 \mu \mathrm{g} / \mathrm{L}$ and 95 th percentile being 4.62 $\mu \mathrm{g} / \mathrm{L}$ and $5.63 \mu \mathrm{g} / \mathrm{L}$ respectively. The median levels are equal to lowest level reported by the tests and are therefore insignificant (Afshari, 2015). Interestingly, the 95th percentile levels for blood mercury are highest in Vancouver Coastal Health Authority for both the above mentioned age groups. Out of 11 individuals who had levels above the current intervention level for this age group, 9 of them were from Vancouver Coastal Health Authority. Among adults, the levels were comparable to other mercury biomonitoring studies with levels increasing with age groups (McKelvey, et al., 2007). Dieticians and physicians usually inform younger population and women of child bearing age to limit their weekly fish consumption (Mercury in Fish, 2015). Blood analysis indicated that 128 women in age of 19-49 had their blood mercury level higher than current intervention level with $46 \%$ of these cases in Vancouver Coastal Health. This indicates that public health intervention is needed to educate this vulnerable population group. The age group 50 and older had highest blood mercury levels in our study and significantly different from other age groups $(p<0.0001)$. This might be due to higher fish consumption in older adults than young. Amount of fish that can be consumed by an adult is approximately 8 times the fish that can be consumed by younger children which might be causing elevated levels in adults (Mercury in Fish, 2015). Older people should also be educated about adequate fish consumption and the possible health effects associated with over consumption of certain food items. 


\section{Lead}

Blood lead levels from this analysis were very close to levels listed in CHMS survey for comparable age groups. $63 \%$ of patients tested for lead in BC during the time frame of 2009-10 fell under two categories namely $<=5$ and 6 to 18 , suggesting that physicians are more likely to order a blood lead test for these age categories. As suggested by previous research, children are most likely to become exposed to lead from their surroundings (lead paint, toys) or during pregnancy (Abelsohn \& Sanborn, 2010; Taylor, Camenzuli, Kristensen, Forbes, \& Zahran, 2013). For other age groups, lead levels followed a trend similar to blood mercury levels with median levels higher in adults. Occupational exposure is often associated with elevated blood levels of lead in adults (Riva, Lafranconi, D’orso, \& Cesana, 2012).

\section{Lead and mercury among different Health Authorities}

\section{Mercury}

Comparing the blood levels of mercury among different health authorities generated some interesting patterns. Mahaffey and colleagues looked at the National Health and Nutrition Examination Survey (NHANES) data from 1999-2004 to examine association between fish consumption, geographical location and levels of mercury among adult women's blood. They found that highest exposure to methyl mercury occurred in coastal areas (Mahaffey, Clickner, \& Jeffries, 2009). Similarly in this study, blood mercury levels were analyzed among Health Authorities and it was found that median blood mercury levels in coastal areas (Vancouver Coastal Health, Fraser Health and Vancouver Island Health Authority) were higher than non-coastal areas ( $p<$ 0.05) (Interior Health and Northern Health). The Canadian Aquaculture Industry Alliance (2013) reported that British Columbians ate fish more often than average Canadians. Residents of BC also had higher consumption of shellfish than Canadian average as well (Farmed Seafood and Canadian Health: Higher Seafood Consumption Can Save Lives, 2013). Therefore, it is not surprising to see levels higher than Canadian average in coastal areas of BC (CHMS: Cycle 2 Data Tables - 2009 to 2011, 2011).
Lead

The median blood lead levels were fairly similar among different Health Authorities. Among those who were tested, Interior Health and "Unknown" had highest median blood lead levels $(1.66 \mu \mathrm{g} / \mathrm{dL})$. These levels were however not significantly different from levels in Vancouver Island Health Authority $(p=0.464)$. However, Vancouver Island Health Authority and Northern Health only had fewer than 30 patients tested for blood lead levels. Therefore, these results cannot be considered representative of these Health Authorities. It could be speculated that majority of these samples could have been taken in Trail BC area (site of an active lead-zinc smelter), due to higher risk of occupational exposure to lead. This community has been monitoring blood lead levels in children since 1989. Results from 2011 annual lead testing in residents of Trail BC, found an average blood lead levels at $5.4 \mu \mathrm{g} / \mathrm{dL}$ (The Canadian Press, 2012). This is an indication of anomalous higher blood lead levels in Trail area of Interior Health Authority which could have affected the median blood lead levels of the whole health region. However, number of people in the Interior Health Authority who could have been tested via WorkSafe BC or through the Trail Area Health and Environment (THE) Program was not known.

\section{Limitations}

Some of the limitations of the study are as follow:

1. A large number of data points fell into the category of Unknown Health Authority (Lead 11.73\%, Mercury $55.42 \%$ ). It is not possible to measure the trend among Health Authorities without considering the difference that information would have made.

2. Multiple testing could not be identified from the lead and mercury data. Data may include the results from the same person tested multiple times at the same provincial laboratory or at a different laboratory.

3. The age of the patients tested was not provided due to privacy concerns. Only age group information was given. This hindered representation of blood lead and mercury concentrations on a level finer than age groups. 
4. Population estimates used to calculate the prevalence data was based on 2011 census and not 2009-2010.

5. Data is not a representative of the general population of $\mathrm{BC}$ as these tests were ordered by physicians after suspected heavy metal exposure.

\section{Conclusion}

Limited information existed regarding blood mercury and lead concentrations for the population of British Columbia. The national data provided by Canadian Health Measures Survey does not provide province wide representation. The statistical analysis of lead and mercury data was useful in characterizing the exposure among Health Authorities, age and sex of the people tested in province of British Columbia. Risk characterization of lead and mercury can provide risk managers and decision makers within Health Authorities, an understanding of goals to be satisfied to mitigate the risk. Analysis of mercury data has generated clear patterns inferring association between coastal Health Authorities and elevated mercury levels. Vancouver Coastal Health had highest median mercury levels $4.02 \mu \mathrm{g} / \mathrm{L}$ higher than other health authorities $(p<0.0001)$. Analysis of lead data established a pattern among physicians suggesting that they are more likely to order a test if the patient is under 18 years of age. The median concentrations based on this data indicate that mercury and lead poisoning are not a significant health concerns in any of Health Authorities in BC, but in order to gain better insight more representative sampling is required. Yearly monitoring results of these two toxic metals will provide public health officials an important tool to educate vulnerable population groups.

\section{Recommendations}

Lead and mercury are have major public health importance. Analysis of mercury data showed that 249 individuals in BC had blood mercury higher than the safe level showing a prevalence 6 individuals per 100 , 000. For lead data, this number was 50 individuals and prevalence being 1 per 100, 000 . These numbers highlight an area that needs public health intervention. Public health interventions in the past have reduced the probability of elevated exposure to these metals in BC. Based on this study some of these recommendations can be suggested to further help reduce the burden of these two metals on public health:

1. Coastal Health authorities need to allocate their resources into educational and health promotion programs to inform the public about mercury exposure associated with fish consumptions.

2. Public health professionals (environmental health officers \& medical health officers) can help devise policies for local food premises to limit the consumption of (fish associated with mercury) by limiting the serving sizes.

3. A high percentage of blood lead samples were obtained from children. Public Health officials need to follow up on the cases that were above the intervention levels ( 24 children) to mitigate the conditions that are causing the exposure.

\section{Future student research projects}

Students can engage in following research projects in future based on this study:

1. Evaluating the menus of food premises serving the fish associated with mercury (fresh/frozen tuna, shark, swordfish, escolar, marlin, and orange roughy) to see if serving sizes are based on Health Canada consumption advice.

2. Survey restaurant operators and people eating at restaurants serving fish on the menu about their knowledge of mercury exposure.

3. Perform a statistical analysis of current (or post 2010) blood mercury or blood lead levels data to establish a trend among the population of British Columbia.

4. Survey people about their knowledge of presence of lead in cookware and their knowledge of health Canada guidelines about buying/importing cooking utensils from other countries.

\section{Acknowledgements}

The authors thank Dr. Tom Kosatsky for providing access to the data used for analysis in this project. Special thanks to Dr. Reza Afshari and British Columbia Institute of Technology - Environmental Health for supporting this research. 


\section{Competing Interests}

The authors declare that they have no competing interests.

\section{References}

(NIOSH), N. I. (2013, September 30). Retrieved October 19, 2015, from CDC - Lead - NIOSH Workplace Safety and Health Topic: http://www.cdc.gov/niosh/topics/lead/defa ult.html

Abadin, H., Ashizawa, A., Stevens, Y.-W., Division of Toxicology and Environmental Medicine, A., Fernando, L., Diamond, G., . . . Syracuse Research Corporation. (2007). Toxicological Profile for Lead. Atlanta, GA: Agency for Toxic Substances and Disease Registry (US). Retrieved from http://www.ncbi.nlm.nih.gov/books/NBK15 8769/

Abelsohn, A. R., \& Sanborn, M. (2010, June). Lead and children - Clinical management for family physicians. Can Fam Physician, 56. Retrieved October 11, 2015, from http://www.ncbi.nlm.nih.gov/pmc/articles/ PMC2902938/pdf/0560531.pdf

Afshari, R. (2015, November 5). Email Conversation.

Brodkin, E., Copes, R., Mattman, A., Kennedy, J., Kling, R., \& Yassi, A. (2007, January 2). Lead and mercury exposures: interpretation and action. Canadian Medical Association Journal, 176(1), 59-63. doi:10.1503/cmaj.060790

Canadian Health Measures Survey: Cycle 2 Data Tables - 2009 to 2011. (2011). Retrieved March 2, 2016, from Statistics Canada: http://www.statcan.gc.ca/pub/82-003x/2008004/article/6500106-eng.htm

Environment Canada. (2010, September 9). Risk management strategy for mercury. Retrieved January 10, 2016, from Environment Canada: http://www.ec.gc.ca/doc/mercuremercury/1241/index_e.htm\#goto230

Evens, A., Hryhorczuk, D., Lanphear, B. P., Rankin, K. M., Lewis, D. A., Forst, L., \& Rosenberg, D.
(2015, April). The impact of low-level lead toxicity on school performance among children in the Chicago Public Schools: a population-based retrospective cohort study. Environmental Health, 14(21). doi:10.1186/s12940-015-0008-9

Farmed Seafood and Canadian Health: Higher Seafood Consumption Can Save Lives. (2013). Retrieved March 1, 2016, from The Canadian Aquaculture Industry Alliance: https://www.google.ca/url?sa=t\&rct=j\&q=\& esrc $=$ s \& source $=$ web $\& c d=1 \& c a d=r j a \& u a c t=8$ \&ved=0ahUKEwjO-

MTw4a3LAhVHwmMKHVIfARQQFggcMAA\& url=http\%3A\%2F\%2Fwww.aquaculture.ca\% 2Ffiles\%2Fdocuments\%2F2013-1119FarmedSeafoodandCanadianHealth_Pape r.pdf\&usg=AFQjCNG2pCp8yPrcVmK

Health Canada. (2009, March 2). It's Your Health Mercury and Human Health. Retrieved January 10, 2016, from Health Canada: http://www.hc-sc.gc.ca/hl-vs/iyhvsv/environ/merc-eng.php

Health Canada. (2013). Final Human Health State of Science Report on Lead. Ottawa: Minister of Health. Retrieved from http://www.hcsc.gc.ca/ewhsemt/alt_formats/pdf/pubs/contaminants/ dhhssrl-rpecscepsh/dhhssrl-rpecscepsheng.pdf

Health Canada. (2013). It's Your Health - Lead and Human Health. Retrieved October 11, 2015, from

http://publications.gc.ca/collections/collect ion_2013/sc-hc/H13-7-101-2013-eng.pdf

Health Canada. (2013). Risk Management Strategy for Lead. Ottawa: Health Canada. Retrieved October 12, 2015, from http://www.hcsc.gc.ca/ewhsemt/pubs/contaminants/prms_leadpsgr_plomb/index-eng.php

Karagas, M. R., Choi, A. L., Oken, E., Horvat, M., Schoeny, R., Kamai, E., . . Korrick, S. (2012, June). Evidence on the Human Health Effects of Low-Level Methylmercury Exposure. 
Environmental Health Perspectives, 120(6). doi:10.1289/ehp.1104494

Lambrinos, A. (2014). Testing for Blood Mercury Levels in the General Population. Retrieved March 2, 2016, from Health Quality Ontario: http://www.hqontario.ca/evidence/publica tions-and-ohtac-recommendations/rapidreviews.

Mahaffey, K. R., Clickner, R. P., \& Jeffries, R. A. (2009). Adult Women's Blood Mercury Concentrations Vary Regionally in the United States: Association with Patterns of Fish Consumption (NHANES 1999-2004). Environmental Health Perspectives, 117, 4753. Retrieved March 2, 2016, from http://www.ncbi.nlm.nih.gov/pmc/articles/ PMC2627864/

McKelvey, W., Gwynn, R. C., Jeffery, N., Kass, D., Thorpe, L. E., Garg, R. K., . . . Parsons, P. J. (2007). A Biomonitoring Study of Lead, Cadmium, and Mercury in the Blood of New York City Adults. Environmental Health Perspectives, 115(10). Retrieved March 6, 2016, from http://www.ncbi.nlm.nih.gov/pmc/articles/ PMC2022653/

Mercury in Fish. (2015). Retrieved March 1, 2016, from Health Canada: http://www.hcsc.gc.ca/fn-an/securit/chemchim/environ/mercur/cons-adv-etudeng.php

Mergier, D., Anderson, H. A., Chan, L. H., Mahaffey, K. R., Murray, M., Sakamoto, M., \& Stern, A. H. (2007). Methylmercury Exposure and Health Effects in Humans: A Worldwide Concern. Ambio, 36(1), 3-11. Retrieved January 12, 2016, from http://0www.jstor.org.innopac.lib.bcit.ca/stable/43 15779

Microsoft Excel 2013. (2013). Retrieved from Microsoft Office: https://support.office.com/en-us/excel

Population by year, by province and territory. (2015). Retrieved March 1, 2016, from Statistics Canada: http://www.statcan.gc.ca/tables-
tableaux/sum-som/I01/cst01/demo02aeng.htm

Riva, M. A., Lafranconi, A., D’orso, M. I., \& Cesana, G. (2012, March). Lead Poisoning: Historical Aspects of a Paradigmatic "Occupational and Environmental Disease. Safety and Health at Work, 3(1). Retrieved October 18, 2015, from

http://dx.doi.org/10.5491/SHAW.2012.3.1. 11

Rochaa, E. D., Sarkisb, J. E., Carvalho, M. d., Santos, G. V., \& Canesso, C. (2014). Occupational exposure to airborne lead in Brazilian police officers. International Journal of Hygiene and Environmental Health, 217, 702-704. Retrieved October 19, 2015, from http://dx.doi.org/10.1016/j.ijheh.2013.12.0 04

Rooney, A. A., Boyles, A. L., Taylor, K., Howdeshell, K., Walker, V. R., Shelby, M. D., \& Thayer, K. A. (2012). NTP Monograph on Health Effects of Low Level Lead. Retrieved October 11, 2015, from National Toxicology Program : http://ntp.niehs.nih.gov/ntp/ohat/lead/fina I/monographhealtheffectslowlevellead_ne wissn_508.pdf

SAS University Edition. (2015). Retrieved from http://www.sas.com/en_us/software/unive rsity-edition.html

Solan, T. D., \& Lindow, S. W. (2014). Mercury exposure in pregnancy: a review. Journal of Perinatal Medicine, 42(6), 725-729. doi: 10.1515/jpm-2013-0349

Stares, J., \& Kostasky, T. (2014). Indicators of Exposure to and Health Effects of Lead in British Columbia, 2009-2010. Vancouver: Environmental Health Services. Retrieved September 28, 2015, from http://www.bccdc.ca/NR/rdonlyres/8EE720 67-D70B-4D78-B9C468EAED725742/0/BL_Surveillance_Report_ V4_SEPT2BEtrs.pdf

Statistics Canada. (2013). Blood lead concentrations in Canadians, 2009-2011. Health Statistics Divison. Minister of Industry, 2013. Retrieved October 12, 2015, from 
http://www.statcan.gc.ca/pub/82-625-

x/2013001/article/11779-eng.pdf

Statistics Canada. (2015, November 27). Lead, mercury and cadmium concentrations in Canadians, 2013 and 2013. Retrieved January 10, 2016, from Statistics Canada: http://www.statcan.gc.ca/pub/82-625-

x/2015001/article/14209-eng.htm

Taylor, C. M., Golding, J., Hibbeln, J., \& Emond, A. M. (2013, September 5). Environmental Factors Predicting Blood Lead Levels in Pregnant Women in the UK: The ALSPAC Study. (A. Chen, Ed.) PLOS One, 8(9). doi:10.1371/journal.pone.0072371

Taylor, M. P., Camenzuli, D., Kristensen, L. J., Forbes, M., \& Zahran, S. (2013). Environmental lead exposure risks associated with children's outdoor playgrounds. Environmental Pollution, 178, 447-454. Retrieved October 16, 2015, from http://dx.doi.org/10.1016/j.envpol.2013.03. 054

The Canadian Press. (2012, December 16). Trail, B.C., smelter decision may have ripple effect. Retrieved April 30, 2016, from CBC: http://www.cbc.ca/news/canada/britishcolumbia/trail-b-c-smelter-decision-mayhave-ripple-effect-1.1180904

Worksafe BC. (2006). Lead - Preventing exposure at work. Worker's Compensation Board of British Columbia. Retrieved October 12, 2015, from http://www.worksafebc.com/publications/ health_and_safety/by_topic/assets/pdf/lea d.pdf 